\title{
Upregulation of PD-1 expression on circulating CD8+ but not CD4+ T cells is associated with tuberculosis infection in health care workers
}

Cui-lin Shi ${ }^{1,2+}$, Jian-ping Zhang ${ }^{2 \dagger}$, Ping $\mathrm{Xu}^{2 \dagger}$, Jin $\mathrm{Li}^{2}$, Jie Shen ${ }^{2}$, Mei-ying $\mathrm{Wu}^{2}$, Zhi-jian $\mathrm{Ye}^{2}, \mathrm{Xin} \mathrm{Yu}^{2}$, Hua-feng Song ${ }^{2}$, Hui Chen ${ }^{2}$, Jun-chi $X^{2^{*}}$, Yu Pang ${ }^{3^{*}}$ and Jian-an Huang ${ }^{1^{*}}$

\begin{abstract}
Background: Health care workers (HCWs) are at risk for occupationally acquired Mycobacterium tuberculosis infection and tuberculosis (TB) disease due to repeated exposure to workplace tubercle bacilli. To determine whether continual mycobacterial stimulation correlates with increased expression of inhibitory $T$ cell receptors, here we compared PD-1 receptor expression on surfaces of circulating T cells between naïve (uninfected) HCWs and HCWs with latent TB infection (LTBI).

Result: Data collected from 133 medical workers who met study selection criteria were included in the final analysis. QuantiFERON-TB Gold In-Tube (QFT-GIT) testing yielded positive results for $32 \mathrm{HCWs}$, for an overall LTBI rate of $24.1 \%$. Multivariate analysis identified HCW length of service $>15$ years as an independent risk factor for a positive QFT-GIT result. In addition, comparisons of blood T cell subgroup profiles between QFT- and QFT+ groups indicated QFT+ subjects possessed greater proportions of mature (TM), transitional memory (TTM) and effector memory (TEM) CD4+ T cell subgroups and lower proportions of naïve T cells (TN). Moreover, the QFT+ group percentage of CD8+ T cells with detectable surface PD-1 was significantly higher than the corresponding percentage for the QFT- group. Meanwhile, no statistical intergroup difference was observed in percentages of CD4+ T cells with detectible surface PD-1.

Conclusions: Our data demonstrated that upregulated PD-1 expression on circulating CD8+, but not CD4+ T cells, was associated with latent TB infection of HCWs. As compared to other hospitals, occupational TB infection risk in our hospital was substantially mitigated by implementation of multitiered infection control measures.
\end{abstract}

Keywords: Health care worker, Latent tuberculosis infection, PD-1, Immunodepletion, T cell

\footnotetext{
*Correspondence: 244957345@qq.com; pangyupound@163.com;

huang_jian_an@163.com

${ }^{+}$Cui-lin Shi, Jian-ping Zhang and Ping Xu contributed equally to this work.

${ }^{2}$ The Fifth People's Hospital of Suzhou (The Affiliated Infectious Diseases

Hospital of Soochow University), 215131, Suzhou, Jiangsu Province, China

${ }^{3}$ Department of Bacteriology and Immunology, Beijing Chest Hospital, Capital

Medical University, Beijing Tuberculosis and Thoracic Tumor Institute, Beijing

101149, Beijing, China

'Department of Pulmonary and Critical Care Medicine, The First Affiliated

Hospital of Soohow University, Suzhou 215006, Jiangsu Province, China
}

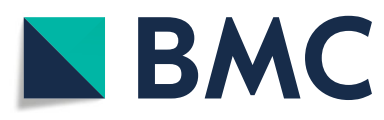

(c) The Author(s). 2021 Open Access This article is licensed under a Creative Commons Attribution 4.0 International License, which permits use, sharing, adaptation, distribution and reproduction in any medium or format, as long as you give appropriate credit to the original author(s) and the source, provide a link to the Creative Commons licence, and indicate if changes were made. The images or other third party material in this article are included in the article's Creative Commons licence, unless indicated otherwise in a credit line to the material. If material is not included in the article's Creative Commons licence and your intended use is not permitted by statutory regulation or exceeds the permitted use, you will need to obtain permission directly from the copyright holder. To view a copy of this licence, visit http://creativecommons.org/licenses/by/4.0/. The Creative Commons Public Domain Dedication waiver (http://creativecommons.org/publicdomain/zero/1.0/) applies to the data made available in this article, unless otherwise stated in a credit line to the data. 


\section{Introduction}

Tuberculosis (TB), caused by Mycobacterium tuberculosis complex, has great significance for public health worldwide, with an estimated one-third of the world's population harboring latent TB infection (LTBI) [1, 2]. Importantly, LTBI serves as the source of all new incident cases of active TB disease, highlighting the fact that the target goal of eliminating TB worldwide by 2035 cannot be achieved without addressing LTBI in populations $[3,4]$. In order to prevent LTBI, aggressive strategies are necessary to halt LTBI disease progression to active TB in order to break the cycle of transmission that continues to fuel the current worldwide TB epidemic. Nevertheless, implementation of such strategies alone will be insufficient for eradicating TB, since continually increasing LTBI burden in vulnerable populations must also be addressed [4]. Ultimately, a better understanding of the pathogenesis of latent TB infection would greatly facilitate development of targeted interventions to recognize and protect naïve individuals from TB infection.

As a significant occupational health problem, health care workers (HCWs) are at high risk of TB exposure [5, 6]. In a recent systematic review, HCWs in low- and middle-income countries continue to possess unacceptably high TB infection incidence and prevalence rates, with prevalence ranging from 9 to 86\% [7]. Previously reported independent risk factors for LTBI have included a greater number of years of service, work location and TB patient contact [8-10]. Although the World Health Organization (WHO) has endorsed implementation of infection control measures to protect HCWs, a highly vulnerable group [11], we believe that greater emphasis should be placed on discovering novel biomarkers with improved performance and predictive value toward monitoring and reducing HCW TB infection risk.

In healthy adults, properly functioning innate and adaptive immune systems are vital for controlling and eradicating $M$. tuberculosis infection [12]. As part of the human adaptive immune system, $\mathrm{T}$ lymphocytemediated cellular immunity is central to the protective M. tuberculosis response [13]. Under conditions of chronic antigen stimulation, such as persistent infection and cancer, $\mathrm{T}$ cell effector functions can be dampened by activities of $\mathrm{T}$ cell inhibitory receptors, a state termed "exhaustion" [14]. HCWs are at particularly high risk for infection with occupationally acquired $M$. tuberculosis that can progress to active TB disease after persistent exposure to tubercle bacilli [2]. The question has been raised as to whether such continuous mycobacterial stimulation in health care settings correlates with increased expression of inhibitory receptors on $\mathrm{T}$ cells that supports high HCW TB infection rates. In this study, we compared PD-1 expression on circulating $\mathrm{T}$ cells obtained from naïve (uninfected) HCWs and HCWs latently infected with $M$. tuberculosis. Our objective was to elucidate the role of $\mathrm{T}$ cell exhaustion in $\mathrm{TB}$ infection to gain valuable insights to guide the development of strategies to halt the unrelenting spread of tuberculosis.

\section{Materials and methods Subjects}

Research related to use of human subjects as was conducted in this study complied with all relevant national regulations, institutional policies and tenets of the Helsinki Declaration. The design of this study has been approved by the Ethics Committee of the Fifth People's Hospital of Suzhou. Informed consent was obtained from all participants prior to initiation of the study. We recruited medical HCWs from the Fifth People's Hospital of Suzhou who engaged in high-risk duties involving exposure to TB patients. Study subjects included clinical physicians, nurses, imaging department workers and laboratory workers. A total of $153 \mathrm{HCWs}$ were initially screened in our study. Exclusion criteria included previous history of tuberculosis, any radiological indicator suggestive of tuberculosis, immune dysfunction, pregnancy and breastfeeding. Ultimately, $133 \mathrm{HCWs}$ who met study selection criteria were included in our final analysis (Fig. 1). Of these, $32 \mathrm{HCWs}$ in the QFT+ group were successfully matched according to sex and age to 31 subjects in the QFT- group to create 31 clinical QFT+/QFT- subject pairs who provided blood for flow cytometric analyses.

\section{QuantiFERON-gold in-tube (QIF-GIT) assay}

Blood samples were obtained after subjects fasted overnight through early morning. For each subject, three heparin tubes were collected: (1) a negative-control tube (NIL tube), (2) an antigen tube (AG tube) containing a coating of specific Mycobacterium tuberculosis antigens (ESAT-6, CFP-10, TB 7.7) that came into contact with the subject's $\mathrm{T}$ cells in the blood sample) and (3) a

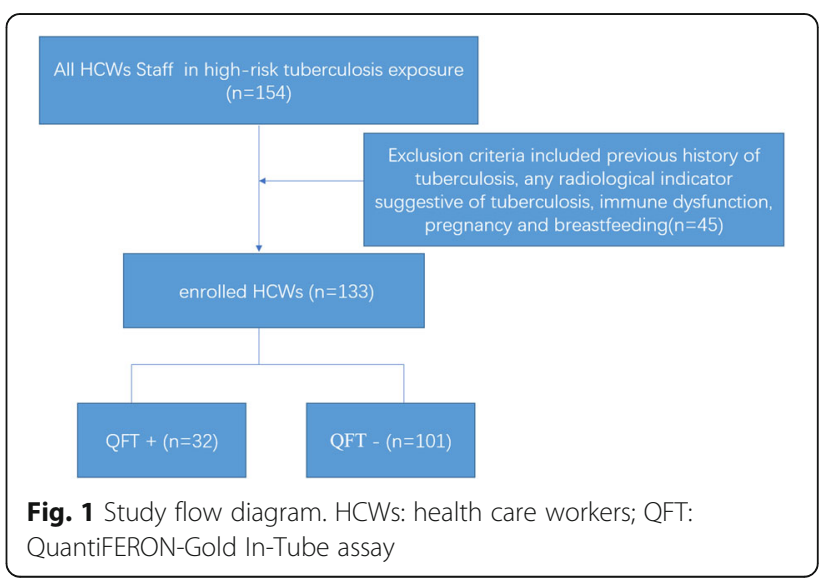


positive-control tube containing phytohemagglutinin-P (PHA) (MIT tube). The concentration of IFN- $\gamma$ secreted by $\mathrm{T}$ cells was measured by ELISA. The results were measured in $\mathrm{IU} / \mathrm{ml}$ and interpreted in accordance with the manufacturer's recommendations as negative, positive or indeterminate [15].

\section{Flow cytometric analysis}

Fluorochrome-labeled monoclonal antibodies CD45RA, CD45RO, CCR7, CD4, CD8 and HLA-DR were purchased from BD Pharmingen (San Diego, CA, USA) and used for flow cytometry based on a gating strategy as previously reported [16]. For each test, $50 \mu \mathrm{L}$ of fresh heparinized whole blood of test subjects or healthy donors was incubated with indicated antibodies $(10 \mu \mathrm{L})$ for 15 min then lysed with FACSTM lysing solution (BD Biosciences, San Jose, CA, USA). Samples were subsequently washed with phosphate buffered saline, fixed then subjected to flow cytometric analysis using a BD FACSAria system with BD FACSDiva software.

\section{Statistical analysis}

All data were analyzed using Graph Pad Prism 5.0 software and SPSS 22.0 and were presented as means \pm the standard deviations (SDs). Mann-Whitney U-test and Student's t-test were used for the continuous variables such as mean of the age, and chi-square test was used to compare the categorical variables. Associations between risk factors and QFT results were evaluated using multivariate logistic regression analysis; a two-tailed $p<0.05$ was considered statistically significant.

\section{Results}

\section{Latent TB infection in HCWs}

A total of $133 \mathrm{HCWs}$ were included in our analysis. Baseline characteristics and absolute numbers of $\mathrm{HCW}$ subjects are shown in Table 1 . The majority of HCWs were female $(n=105,78.9 \%)$. The HCW median age was 35.1 years and the median number of years of service was 12.5 years. More than $59.4 \%$ of participants were nurses working in TB facilities. Diabetes and hypertension were noted in $4(3.0 \%)$ and $5(3.8 \%)$ participants, respectively.

\section{Risk factors for latent TB infection in HCWs}

We further analyzed risk factors for latent TB infection in HCWs in our cohort. Among the HCWs, blood of 101 subjects tested negative by QFT-GIT, while the other 32 subjects had positive QFT-GIT results, for an overall HCW LTBI rate of $24.1 \%$. Results of analysis of relationships among demographic and clinical characteristics and QFT-GIT responses are summarized in Table 1. The highest LGBI prevalence rate was found in nurses $(21 / 133,65.7 \%)$ and the second-highest rate as found in doctors $(11 / 133,34.3 \%)$. Notably, no laboratory staff or radiologists tested positive via QFT-GIT, while a high number of years of practice was significantly associated with increased TB risk. By contrast, no correlation was found between LTBI status and differential white blood cell count. Meanwhile, multivariate analysis revealed that independent risk factors for positive QFT-GIT results included number of years of service as a $\mathrm{HCW}$ of $>15$ years [adjusted odds ratio (aOR): $0.249,95 \%$ confidence interval (95\% CI): 0.090-0.686, $P=0.007$ ) (Table 2).

\section{Subpopulations of human memory $\mathrm{T}$ cells}

Based on expression of lymphocyte surface biomarkers, human memory $\mathrm{T}$ cells can be categorized according to differentiation stage into mature $(\mathrm{TM})$, naïve $(\mathrm{TN})$, central memory (TCM), transitional memory (TTM), and effector memory (TEM) T cells [17]. We observed that blood of subjects of the QFT+ group contained an overall higher proportion of TM CD4+ T cells than observed for blood of the QFT- group (56.8\% vs. $44.3 \%, P=$ 0.0004). Similarly, higher percentages of TTM and TEM cells were detected in CD4+ cell populations of QFT+ subjects as compared to percentages of both cell types in CD4+ cell populations of QFT- subjects $(44.1 \%$ vs. $36.1 \%$ for TTM, respectively, $P=0.002 ; 12.4 \%$ vs. $7.7 \%$ for TEM, respectively, $P=0.0066$ ). By contrast, the proportion of $\mathrm{TN} \mathrm{T}$ cells of the CD4+ $\mathrm{T}$ cell population (50.5\%) of the QFT- group exceeded that of the QFT+ group (38.8\%, $P=0.001$ ) (Fig. 2).

We also compared CD8+ T cell subpopulations between QFT+ and QFT- groups, with results provided in Fig. 3. Briefly, percentages of various memory $\mathrm{CD} 8+\mathrm{T}$ cell subpopulations in the QFT+ group were comparable to corresponding QFT- group percentages $(P>0.05)$.

\section{Comparison of PD-1 expression on peripheral blood CD4+ and CD8+ T cells}

Using flow cytometry, levels of PD-1 receptors on surfaces of peripheral $\mathrm{T}$ lymphocytes were stratified by $\mathrm{T}$ cell type (CD4+ versus CD8+). As shown in Fig. 4, the overall percentage of QFT + group CD8 $+\mathrm{T}$ cells with detectible surface PD-1 expression was significantly greater than that of the QFT- group (median, $31.6 \%$ vs. $25.3 \%$, $P=0.0278$ ). By contrast, no statistical difference in percentage of $\mathrm{CD} 4+\mathrm{T}$ cells with detectible PD-1 expression was observed between QFT+ and QFT- groups (median, $44.6 \%$ vs. $34.3 \%, P=0.0836$ ). Furthermore, the percentage of all subsets of CD8 $+\mathrm{T}$ memory cells with detectible PD-1 expression in the QFT+ group was significantly greater than that of the QFT- group (Fig. S1). Meanwhile, no statistical difference was observed between QFT + and QFT- groups of percentages of naïve CD4+ T cells with detectible surface PD-1, the main CD4+ T memory cell subset (Fig. S2). 
Table 1 Baseline Characteristics of medical worker

\begin{tabular}{|c|c|c|c|c|c|}
\hline Characteristics & Total & $\mathrm{QFT}+(n=32)$ & QFT - $(n=101)$ & Statistical value & $P$ value \\
\hline \multicolumn{6}{|l|}{ Sex } \\
\hline Male & $28(21.1)$ & $5(15.6)$ & $23(22.8)$ & 0.747 & 0.387 \\
\hline Female & $105(78.9)$ & $27(84.4)$ & 78 (77.2) & & \\
\hline Age & $35.1 \pm 8.4$ & $38.0 \pm 8.0$ & $34.2 \pm 5.2$ & -1.763 & 0.078 \\
\hline Working time (year) & $12.5 \pm 10.0$ & $16.5 \pm 8.5$ & $11.2 \pm 6.2$ & -2.833 & 0.005 \\
\hline$<=2$ & $15(11.3)$ & $1(3.1)$ & $14(13.9)$ & 13.067 & $<0.001$ \\
\hline$(3-5)$ & $20(15.0)$ & 0 & $20(19.8)$ & & \\
\hline$(6-15)$ & $61(45.9)$ & $16(50)$ & $45(44.6)$ & & \\
\hline$(16-25)$ & $12(9.0)$ & $6(18.8)$ & $6(5.9)$ & & \\
\hline$>25$ & $25(18.8)$ & $9(28.1)$ & $16(15.8)$ & & \\
\hline \multicolumn{6}{|l|}{ Occupation } \\
\hline Doctor & $34(25.6)$ & $11(34.3)$ & $23(22.8)$ & 7.891 & 0.048 \\
\hline Nurse & $79(59.4)$ & $21(65.7)$ & $58(57.4)$ & & \\
\hline Laboratory staff & $13(9.8)$ & 0 & $13(12.8)$ & & \\
\hline Radiologist & $7(5.3)$ & 0 & $7(7.0)$ & & \\
\hline \multicolumn{6}{|l|}{ Chronic medical illness } \\
\hline Hypertension & $4(3.0)$ & $2(6.3)$ & $2(2.0)$ & 3.058 & 0.09 \\
\hline Type 2 diabetes & $5(3.8)$ & $3(9.4)$ & $2(2.0)$ & 1.3 & 0.244 \\
\hline \multicolumn{6}{|l|}{ Clinical biochemical index } \\
\hline White blood cell count(WBC), 10^9/L & & $6.063 \pm 0.938$ & $6.701 \pm 1.651$ & -0.993 & 0.321 \\
\hline Lymphocyte count(L), 10^9/L & & $2.059 \pm 0.451$ & $2.131 \pm 0.421$ & -0.704 & 0.481 \\
\hline Alanine aminotransferase(ALT), U/L & & $17.969 \pm 9.469$ & $21.457 \pm 12.707$ & -0.993 & 0.321 \\
\hline Plasma creatinine, $\mu \mathrm{mol} / \mathrm{L}$ & & $59.941 \pm 8.941$ & $63.823 \pm 8.823$ & -1.752 & 0.08 \\
\hline \multicolumn{6}{|l|}{ Cellular immunological index } \\
\hline $\mathrm{CD}^{+} \mathrm{T}$ cell count, $10 \wedge^{9} / \mathrm{L}$ & & $0.727 \pm 0.246$ & $0.763 \pm 0.225$ & 0.772 & 0.442 \\
\hline $\mathrm{CD}^{+} \mathrm{T}$ cell count, $10 \wedge^{9} / \mathrm{L}$ & & $0.569 \pm 0.193$ & $0.558 \pm 0.213$ & -0.263 & 0.793 \\
\hline T cell count, $10 \wedge^{9} / \mathrm{L}$ & & $1.391 \pm 0.283$ & $1.431 \pm 0.315$ & -0.156 & 0.876 \\
\hline B cell count, $10 \wedge^{9} / \mathrm{L}$ & & $0.242 \pm 0.097$ & $0.248 \pm 0.082$ & -0.024 & 0.981 \\
\hline NK cell count, $10 \wedge^{9} / \mathrm{L}$ & & $17.061 \pm 5.231$ & $18.14 \pm 6.205$ & -0.303 & 0.762 \\
\hline
\end{tabular}

Table 2 Univariate and multivariate analysis of factors associated with positive or negative QFT-G result

\begin{tabular}{|c|c|c|c|c|c|c|}
\hline \multirow[t]{2}{*}{ Variable } & \multicolumn{3}{|c|}{ Univariate } & \multicolumn{3}{|c|}{ Multivariate } \\
\hline & OR & $95 \% \mathrm{Cl}$ & $P$ & $\mathrm{OR}$ & $95 \% \mathrm{Cl}$ & $P$ \\
\hline Age & 1.053 & $1.005-1.103$ & 0.029 & & & \\
\hline Sex & 1.592 & $0.551-4.603$ & 0.390 & 0.827 & $0.172-3.973$ & 0.813 \\
\hline work time ( $\leq 15$ vs $>15)$ & 3.168 & $1.368-7.338$ & 0.007 & 0.249 & $0.090-0.686$ & 0.007 \\
\hline Hypertension & 0.303 & $0.041-2.244$ & 0.242 & 0.564 & $0.062-5.097$ & 0.61 \\
\hline Plasma creatinine, $\mu \mathrm{mol} / \mathrm{L}$ & 0.975 & $0.942-1.009$ & 0.146 & 0.969 & $0.923-1.017$ & 0.203 \\
\hline $\mathrm{CD}^{+}{ }^{+} \mathrm{T}$ cell count, $10^{\wedge} \stackrel{\mathrm{L}}{ }$ & 0.997 & $0.937-1.061$ & 0.928 & 0.838 & $0.002-479.941$ & 0.956 \\
\hline $\mathrm{CD}^{+} \mathrm{T}$ cell count, $10^{\wedge 9} / \mathrm{L}$ & 1.038 & $0.981-1.099$ & 0.198 & 23.342 & $0.031-17,527.830$ & 0.351 \\
\hline $\mathrm{T}$ cell count, $10^{\wedge 9} / \mathrm{L}$ & 0.784 & $0.286-2.153$ & 0.637 & 0.810 & $0.004-157.836$ & 0.937 \\
\hline B cell count, $10^{\wedge 9} / \mathrm{L}$ & 0.597 & $0.016-21.626$ & 0.778 & 0.404 & $0.001-136.131$ & 0.76 \\
\hline NK cell count, $10^{\wedge 9} / \mathrm{L}$ & 0.981 & $0.928-1.037$ & 0.495 & 0.452 & $0.028-7.207$ & 0.574 \\
\hline
\end{tabular}




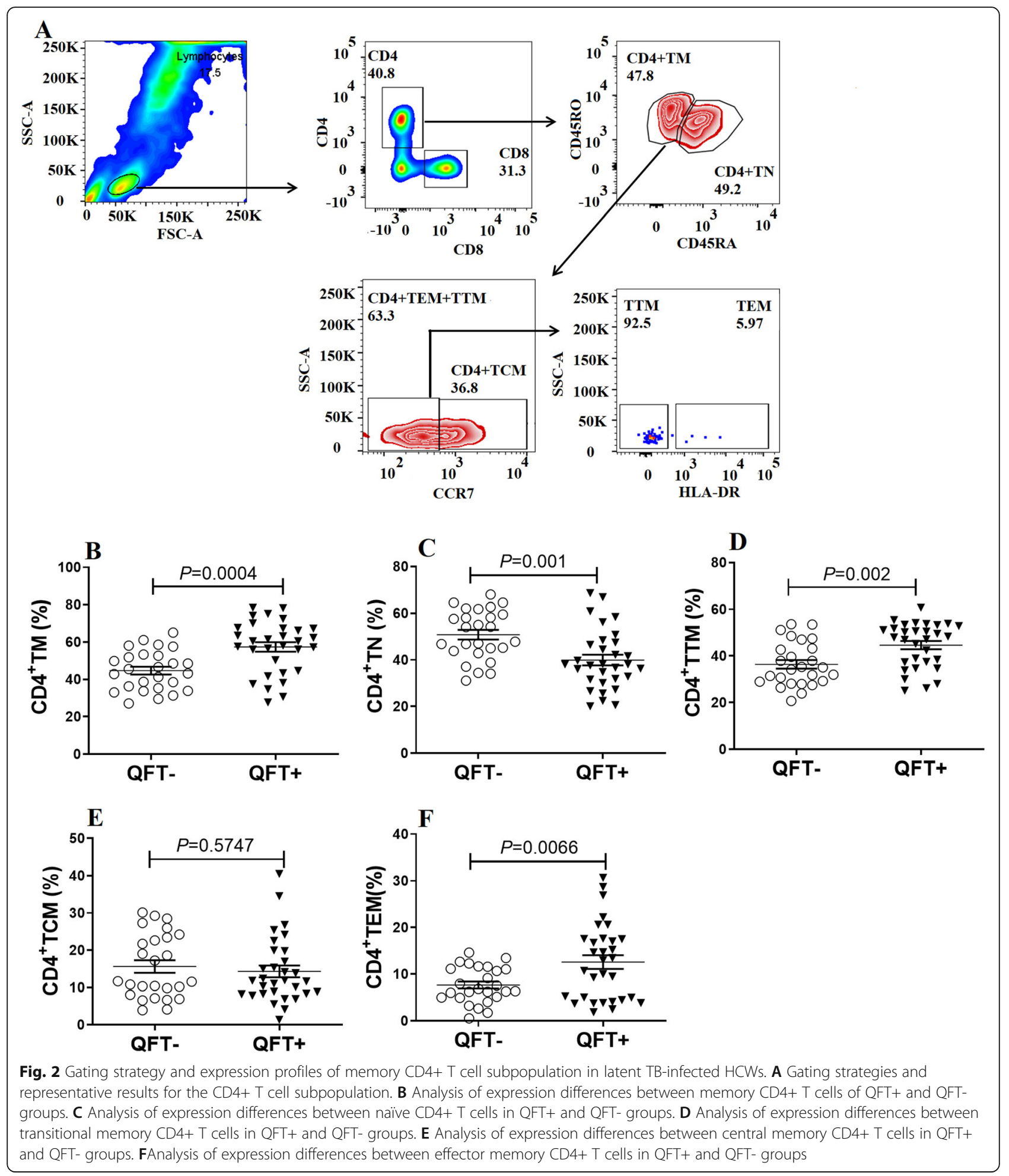

\section{Discussion}

Despite implementation of infection control measures, $\mathrm{HCW}$ remain at high risk of contracting occupational tuberculosis [2]. In this study, our results suggested that nearly one quarter of HCWs in a TB-specialized hospital in China had LTBI, a lower rate than the rate of 39\% reported in a systematic review conducted in HCWs from low- and middle-income countries [7, 18]. Of note, a recent population-based cohort study in China revealed that LTBI prevalence was $19 \%$ in the rural population, a 

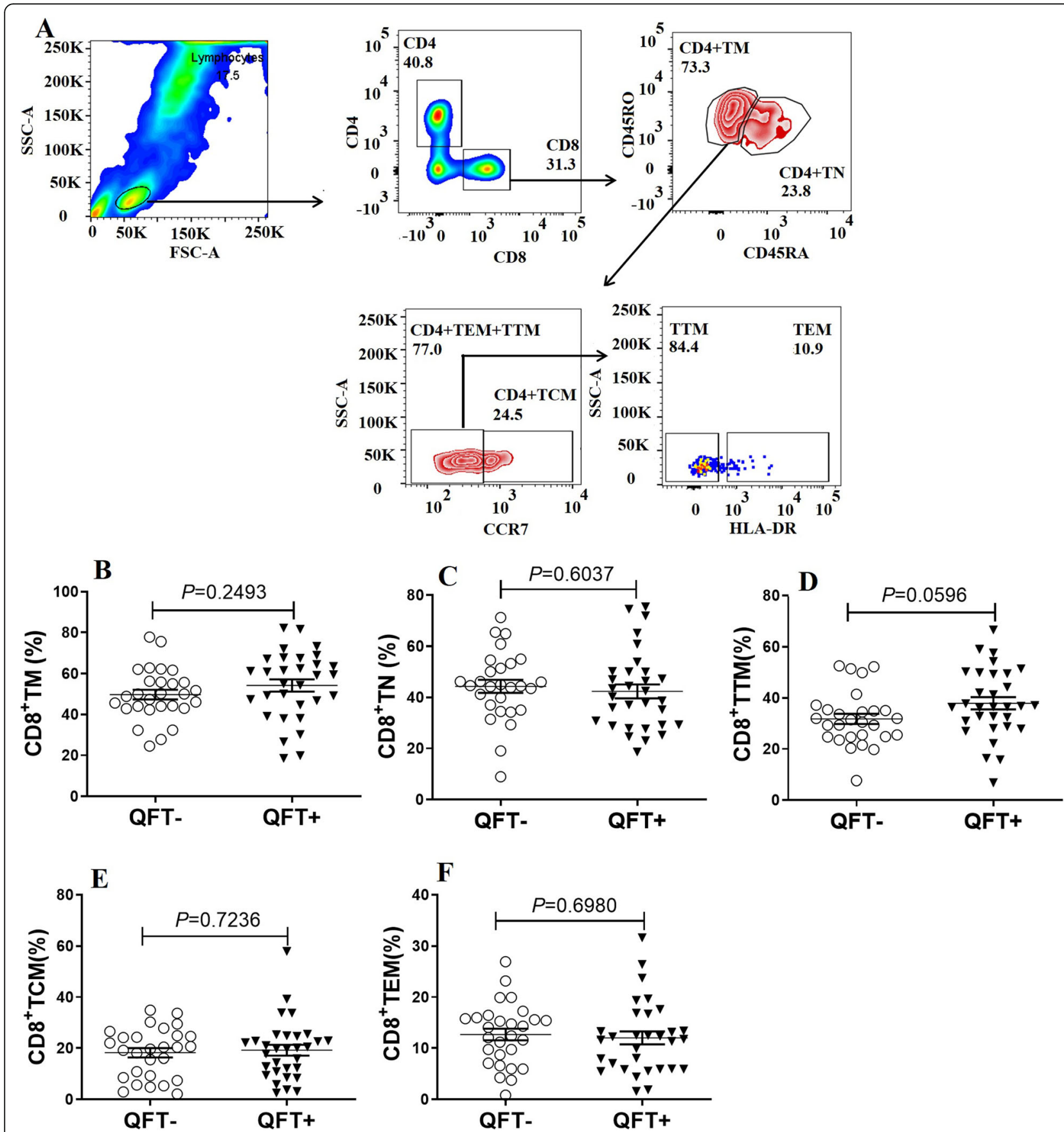

Fig. 3 Gating strategy and the expression profiles of memory CD8+ T cell subpopulation in latent TB-infected HCWs. A Gating strategies and representative results for the CD8+ T cell subpopulation. B Analysis of expression differences between memory CD8+ T cells in QFT+ and QFTgroups. CAnalysis of expression differences between naive CD8+ T cells in QFT+ and QFT- groups. D Analysis of expression differences between transitional memory CD8+ T cells in QFT+ and QFT- groups. EAnalysis of expression differences between central memory CD8+ T cells in QFT+ and QFT- groups. F Analysis of expression differences between effector memory CD8+ T cells in QFT+ and QFT- groups

rate only slightly lower than that found here [18]. There are several explanations for the relatively low rate of LTBI in our report. On the one hand, the prevalence of LTBI generally positively correlates with TB incidence rates across regions. For example, Apriani and colleagues revealed that HCWs from countries with annual $\mathrm{TB}$ incidence rates of $>300 / 100,000$ displayed the highest LGBI prevalence rates [7]. Thus, the relatively lower LTBI rate for HCWs found here likely reflects declining TB incidence in China as compared to other countries [19]. On the other hand, the risk of occupational TB infection has been substantially mitigated by 

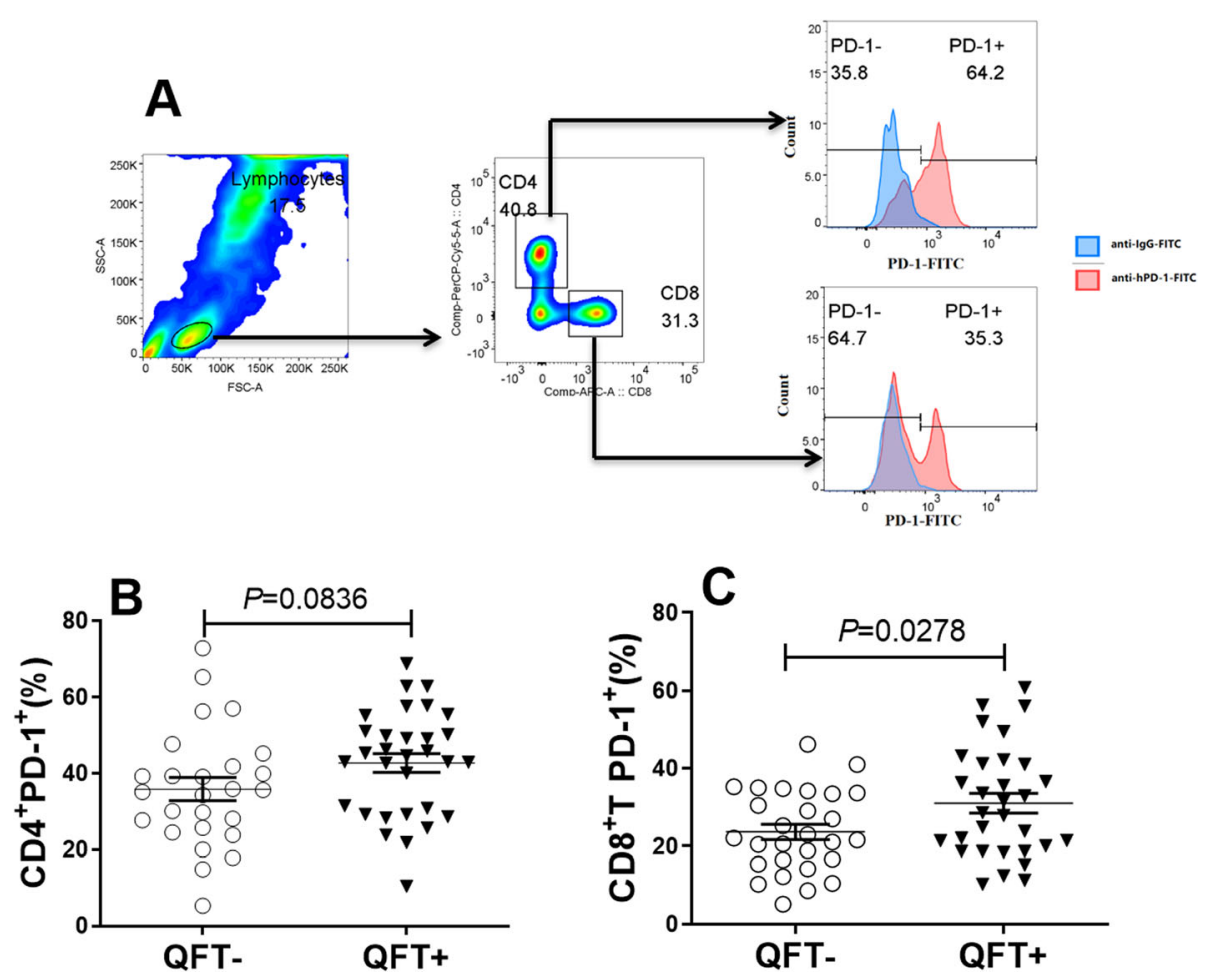

Fig. 4 Expression of PD-1 on T cells in latent TB-infected HCWs. A Gating strategies and representative results related to PD-1 expression on T cells. B Analysis of PD-1 expression differences between CD4+ T cells in QFT+ and QFT- groups. C Analysis of PD-1 expression differences between CD8+ T cells in QFT+ and QFT- groups

implementation of the multi-level infection control approach practices in our hospital, which includes use of N95 masks and negative-pressure patient rooms. Our data confirm that strengthened infection control measures are necessary to reduce risk of TB transmission, especially in high-risk settings where TB patients receive care.

An increased risk of LTBI in healthcare settings has been associated with occupational category, increasing age and length of service $[8,20]$. However, only length of service was found to be an independent risk factor for occupational infection in our cohort. This strong association likely reflects increased risk due to prolonged occupational exposure to TB bacilli, especially in the past when infection control measures were less effective. The fact that older workers are at higher risk of contracting TB may also reflect improvements in TB infection control practices in recent years, thereby decreasing infection risk of younger HCWs with few years of service. A future study to monitor TB conversion in HCWs using an Interferon- $\gamma$ Release Assay (IGRA) will be key to validating our hypothesis.

The interferon gamma release assay (IGRA) is useful for monitoring the establishment and persistence of $\mathrm{T}$ cell memory for identification of LTBI cases. Detailed analysis of memory $\mathrm{T}$ cell subpopulations of QFT+ subjects in this work demonstrated greater proportions of TM CD4+ cells in that group than in the QFT- group, suggesting that the conversion of naive memory CD4+ cells to mature memory CD4+ cells requires continuous antigenic stimulation through prolonged occupational exposure. This interpretation was supported by the observation that a significantly higher proportion of CD4+ TEM, but not CD4+ TCM, was found in the QFT+ group. Our findings raise an interesting question regarding the diminished response of memory CD4+ cells in QFT- individuals. Current evidence suggests that establishment of $\mathrm{T}$ cell memory can be influenced both by antigen dose as well as by antigen presentationassociated factors [21, 22], although exact mechanisms underlying variable $\mathrm{T}$ cell memory remain unclear. Here we hypothesize that macrophages of QFT- HCW subjects may possess greatly enhanced tubercle bacillikilling activity, thereby leading to weak antigen presentation and subsequently diminished memory $\mathrm{T}$ cell proliferation.

Another interesting finding of this study was that immunodepletion of CD8 $+\mathrm{T}$ cells was observed in $\mathrm{QFT}+$ individuals. Of note, QFT+ individuals tend to produce more sustained cytokine responses due to high proportions of TM and TEM CD4+ cells that promote recruitment and activation of CD8+ T cells. Therefore, 
in the face of repeated MTB challenges, homeostatic forces must balance the immunological CD8+ cell response to prevent inflammatory damage [23], while preserving the functionality of CD8+ T cells for combating MTB and other pathogens. Specially, in a report by van Pinxteren and colleagues, depletion of CD8 $+\mathrm{T}$ cells in mice during the chronic stage of TB infection resulted in greater bacterial burden, indicating these $\mathrm{T}$ cells are important for long-term control of MTB infection [24]. Such findings, together with the results of the current study, strongly suggest that the immunodepletion of CD8+ cells in QFT+ HCWs may increase likelihood of latent TB infection that may progress eventually to active TB disease. Therefore, our results highlight an urgent need to identify the dynamics of $\mathrm{HCW} T$ cell subpopulations taking into account variable cell life spans in order to enhance our understanding of immunological mechanisms of human MTB infection.

We also acknowledge several limitations of this study. First, the statistical power of our analysis may be insufficient due to the small sample size in this work of subjects recruited from a single center. Our analysis of risk factors for HCWs with latent TB would greatly benefit from analysis of data drawn from a larger number of subjects to generate results that are statistically more robust. Second, the establishment of immunological memory requires time (several weeks). Thus, the crosssectional design of the present study may lead to underestimation of LTBI prevalence in our HCW cohort. Finally, despite our observation that lower numbers of CD8+ cells were present in subjects who had experienced repeated MTB exposure, it remains unclear whether MTB-specific CD8+ cells were specifically immunodepleted during repeated MTB exposure.

In conclusion, our data first demonstrated that upregulation of PD-1 expression on circulating CD8+, but not CD4+ $\mathrm{T}$ cells, was associated with LTBI of HCWs. Moreover, occupational TB infection risk was substantially mitigated by implementation of a multitiered implementation of infection control measures in our hospital. Only length of service was noted as an independent risk factor for occupational infection. Further study is urgently needed to determine the mechanism of $\mathrm{HCW}$ CD8+ immunodepletion in response to repeated MTB exposure.

\section{Supplementary Information}

The online version contains supplementary material available at https://doi. org/10.1186/s12865-021-00433-9.

Additional file 1: Supplemental Figure 1. The expression of PD-1 of CD4 + T cell subpopulation in latent TB infection HCWs.

Additional file 2: Supplemental Figure 2. The expression of PD-1 of CD8 + T cell subpopulation in latent TB infection HCWs.

\section{Acknowledgements}

None.

\section{Authors' contributions}

All listed authors meet the requirements for authorship. JX, YP and JH designed and supervised the study and revised the manuscript. CS, JZ, JL, JS, MW, ZY, XY and HC collected clinical information and samples. PX and HS conducted laboratory tests. YP analysed and interpreted the data. CS, JZ, and PX wrote the manuscript. All authors critically reviewed and approved the final manuscript.

\section{Funding}

This work was supported by grants from the Science and Technology Plan of Suzhou, China (SYSD2018193, C.S.; SYS 2019111, J.S.; and SS2019010, M.W.). Our research sponsors had no role in the research design, data collection, data analysis, data interpretation, or report writing.

\section{Availability of data and materials}

Datasets obtained and/or analyzed during the current study are available from the corresponding author upon request.

\section{Declarations}

\section{Ethics approval and consent to participate}

All procedures performed in studies involving human participants were in accordance with the ethical standards of the institutional and/or national research committee and with the 1964 Helsinki declaration and its later amendments or comparable ethical standards. This study was approved by the Ethics Committee of The Fifth People's Hospital of Suzhou. All subjects provided signed informed consents prior to inclusion of this analysis.

\section{Consent for publication}

Not applicable.

\section{Competing interests}

None.

Received: 19 March 2021 Accepted: 10 June 2021

Published online: 25 June 2021

\section{References}

1. World Health Organization. Global tuberculosis report. Geneva, Switzerland: World Health Organization; 2020.

2. Zwerling A, van den Hof S, Scholten J, Cobelens F, Menzies D, Pai M. Interferon-gamma release assays for tuberculosis screening of healthcare workers: a systematic review. Thorax. 2012;67(1):62-70. PubMed PMID: 21228420. Epub 2011/01/14. https://doi.org/10.1136/thx.2010.143180.

3. Getahun $\mathrm{H}$, Matteelli A, Chaisson RE, Raviglione M. Latent mycobacterium tuberculosis infection. N Engl J Med. 2015;372(22):2127-35. PubMed PMID: 26017823. Epub 2015/05/29. https://doi.org/10.1056/NEJMra1405427.

4. Rangaka MX, Cavalcante SC, Marais BJ, Thim S, Martinson NA, Swaminathan $\mathrm{S}$, et al. Controlling the seedbeds of tuberculosis: diagnosis and treatment of tuberculosis infection. Lancet. 2015;386(10010):2344-53. PubMed PMID: 26515679. Pubmed Central PMCID: PMC4684745. Epub 2015/10/31. https:// doi.org/10.1016/S0140-6736(15)00323-2

5. Joshi R, Reingold AL, Menzies D, Pai M. Tuberculosis among health-care workers in low- and middle-income countries: a systematic review. PLoS Med. 2006;3(12):e494. PubMed PMID: 17194191. Pubmed Central PMCID: PMC1716189. Epub 2006/12/30. https://doi.org/10.1371/journal.pmed.0030494.

6. Menzies D, Joshi R, Pai M. Risk of tuberculosis infection and disease associated with work in health care settings. Int J Tuberc Lung Dis. 2007; 11(6):593-605 PubMed PMID: 17519089. Epub 2007/05/24.

7. Apriani L, McAllister S, Sharples K, Alisjahbana B, Ruslami R, Hill PC, et al. Latent tuberculosis infection in healthcare workers in low- and middleincome countries: an updated systematic review. Eur Respir J. 2019;53(4) PubMed PMID: 30792341 Epub 2019/02/23.

8. Adams S, Ehrlich R, Baatjies R, van Zyl-Smit RN, Said-Hartley Q, Dawson R, et al. Incidence of occupational latent tuberculosis infection in south African healthcare workers. Eur Respir J. 2015;45(5):1364-73. PubMed PMID: 25700382. Pubmed Central PMCID: PMC5523975. Epub 2015/02/24. https:// doi.org/10.1183/09031936.00138414. 
9. Agaya J, Nnadi CD, Odhiambo J, Obonyo C, Obiero V, Lipke V, et al. Tuberculosis and latent tuberculosis infection among healthcare workers in Kisumu, Kenya. Trop Med Int Health. 2015;20(12):1797-804. PubMed PMID: 26376085. Epub 2015/09/17. https://doi.org/10.1111/tmi.12601.

10. Borroto S, Gamez D, Diaz D, Martinez Y, Ferrer Al, Velasquez Y, et al. Latent tuberculosis infection among health care workers at a general hospital in Santiago de Cuba. Int J Tuberc Lung Dis. 2011;15(11):1510-4, i. PubMed PMID: 22008765. Epub 2011/10/20. https://doi.org/10.5588/ijtld.10.0333.

11. World Health Organization. WHO guidelines on tuberculosis infection prevention and control 2019 update. Geneva, Switzerland: World Health Organization; 2019

12. O'Garra A, Redford PS, McNab FW, Bloom Cl, Wilkinson RJ, Berry MP. The immune response in tuberculosis. Annu Rev Immunol. 2013;31(1):475-527. PubMed PMID: 23516984. Epub 2013/03/23. https://doi.org/10.1146/a nnurev-immunol-032712-095939.

13. Boom WH, Canaday DH, Fulton SA, Gehring AJ, Rojas RE, Torres M. Human immunity to M. tuberculosis: T cell subsets and antigen processing. Tuberculosis (Edinb). 2003;83(1-3):98-106. PubMed PMID: 12758197. Epub 2003/05/22. https://doi.org/10.1016/S1472-9792(02)00054-9.

14. Pauken KE, Wherry EJ. Overcoming T cell exhaustion in infection and cancer. Trends Immunol. 2015;36(4):265-76. PubMed PMID: 25797516. Pubmed Central PMCID: PMC4393798. Epub 2015/03/24. https://doi.org/10.1 016/j.it.2015.02.008

15. Lu P, Liu Q, Zhou Y, Martinez L, Kong W, Ding X, et al. Predictors of discordant tuberculin skin test and QuantiFERON-TB gold in-tube results in eastern China: a population-based, Cohort Study. Clin Infect Dis. 2020: PubMed PMID: 32369577. Epub 2020/05/06.

16. Larbi A, Fulop T. From "truly naive" to "exhausted senescent" T cells: when markers predict functionality. Cytometry A. 2014;85(1):25-35. PubMed PMID: 24124072. Epub 2013/10/15. https://doi.org/10.1002/cyto.a.22351.

17. Perera PY, Lichy JH, Waldmann TA, Perera LP. The role of interleukin-15 in inflammation and immune responses to infection: implications for its therapeutic use. Microbes Infect. 2012;14(3):247-61. PubMed PMID: 22064066. Pubmed Central PMCID: PMC3270128. Epub 2011/11/09. https:// doi.org/10.1016/.micinf.2011.10.006

18. Gao L, Lu W, Bai L, Wang X, Xu J, Catanzaro A, et al. Latent tuberculosis infection in rural China: baseline results of a population-based, multicentre, prospective cohort study. Lancet Infect Dis. 2015;15(3):310-9. PubMed PMID: 25681063. Epub 2015/02/15. https://doi.org/10.1016/S1473-3099(14)71085-0.

19. Wang L, Zhang H, Ruan Y, Chin DP, Xia Y, Cheng S, et al. Tuberculosis prevalence in China, 1990-2010; a longitudinal analysis of national survey data. Lancet. 2014;383(9934):2057-64. PubMed PMID: 24650955. Epub 2014/ 03/22. https://doi.org/10.1016/S0140-6736(13)62639-2.

20. Peters C, Kozak A, Nienhaus A, Schablon A. Risk of occupational latent tuberculosis infection among health personnel measured by interferongamma release assays in low incidence countries-a systematic review and meta-analysis. Int J Environ Res Public Health. 2020;17(2) PubMed PMID: 31963207. Pubmed Central PMCID: PMC7027002. Epub 2020/01/23.

21. Keck S, Schmaler M, Ganter S, Wyss L, Oberle S, Huseby ES, et al. Antigen affinity and antigen dose exert distinct influences on CD4 T-cell differentiation. Proc Natl Acad Sci U S A. 2014;111(41):14852-7. PubMed PMID: 25267612. Pubmed Central PMCID: PMC4205596. Epub 2014/10/01. https://doi.org/10.1073/pnas.1403271111.

22. Rosenblum MD, Way SS, Abbas AK. Regulatory T cell memory. Nat Rev Immunol. 2016;16(2):90-101. PubMed PMID: 26688349. Pubmed Central PMCID: PMC5113825. Epub 2015/12/22. https://doi.org/10.1038/nri.2015.1.

23. Nikolich-Zugich J. Ageing and life-long maintenance of T-cell subsets in the face of latent persistent infections. Nat Rev Immunol. 2008;8(7):512-22. PubMed PMID: 18469829. Pubmed Central PMCID: PMC5573867. Epub 2008/05/13. https://doi.org/10.1038/nri2318.

24. van Pinxteren LA, Cassidy JP, Smedegaard BH, Agger EM, Andersen P. Control of latent mycobacterium tuberculosis infection is dependent on CD8 T cells. Eur J Immunol. 2000;30(12):3689-98. PubMed PMID: 11169412 Epub 2001/02/13. https://doi.org/10.1002/1521-4141(200012)30:12<3689::A ID-IMMU3689>3.0.CO;2-4

\section{Publisher's Note}

Springer Nature remains neutral with regard to jurisdictional claims in published maps and institutional affiliations.

Ready to submit your research? Choose BMC and benefit from:

- fast, convenient online submission

- thorough peer review by experienced researchers in your field

- rapid publication on acceptance

- support for research data, including large and complex data types

- gold Open Access which fosters wider collaboration and increased citations

- maximum visibility for your research: over $100 \mathrm{M}$ website views per year

At BMC, research is always in progress.

Learn more biomedcentral.com/submissions 